\title{
Domesticating distant suffering: How can news media discursively invite the audience to care?
}

Stijn Joye

\begin{abstract}
Several scholars have identified an important emotional role in news media's covering of international disasters; inviting the audience to care for people in need who are not like us. This article addresses the question of how news media can attribute a local sense of relevance to global suffering by focusing on the journalistic practice of domestication. Following a case-based methodology, we investigate how two Belgian television stations have domesticated international disasters in 2011. As the study shows, rendering distant suffering more relevant to local audiences can be realized in several ways. A Critical Discourse Analysis identified four key discursive modes of domestication. By drawing on these modes, news journalists try to incite involvement in their representations of distant suffering, hence inviting the local audience to relate with the distant Other. Domestication can lead to possible feelings of cosmopolitanism and identification, although dominant power relations of global inequality remain largely unchallenged.
\end{abstract}

\section{Introduction}

Each year, disasters cause severe damage and human suffering around the globe. For most people living in western countries, disasters are a priori distant suffering (Boltanski, 1999) as they mainly affect cultural or ethnic others. News media thus play a pivotal role in giving publicity and meaning to these numerous instances of global suffering as it is essentially through media reports that the western world perceives international disasters (Franks, 2008; Benthall, 2010). Accordingly, the most common grief and death experience of contemporary western audiences is a mediated experience of indirect exposure to instances of human suffering (Kitch and Hume, 2007). Next to the news media's primary informational role, several scholars such as Chouliaraki (2006), Pantti (2009) and Kyriakidou (2011) thus identified an important emotional role in news media's covering of international disasters: that is inviting the audience to care or to feel compassion for people who are not like us.

In this article, we address the question of how news media can attribute a local sense of relevance to an international news event by focusing on the practice of domestication (Clausen, 2004). The theoretical framework integrates theories and concepts that were developed within the field of disaster studies and the representation of (distant) suffering. Applying Critical Discourse Analysis (CDA), the cases of this study are 87 news items on international disasters that were broadcast by Belgian television channels VRT and VTM in 2011. Our empirical focus lies on domesticated news items that echo a particular kind of enforced proximity (cf. concept of cosmopolitanism as defined by Tomlinson, 1999) but also hint at Silverstone's (2007) notion of proper distance which refers to a particular politics of the representation of otherness and our mediated relationship to the other, fostering an ethics of care. The latter further resonates with Cottle's idea of a mediated ethics of care, 'an invitation [inscribed in media] to recognize, better understand and care about the plight of others' (2009: 93). Central to this study are two research questions: Which discursive strategies of domestication are applied by news media in their 
coverage of distant suffering? And how can these strategies invite audiences to relate with the distant Other and thus lead to a sense of an enforced proximity which is the key aspect of domestication as journalistic practice?

\section{Theoretical background}

Within the academic field of international news studies the concept of domestication is gaining in significance as scholars have reflected upon the emerging tensions between tendencies of globalization on the one hand and localization on the other (Biltereyst and Desmet, 2010; Berglez, 2013; Olausson, 2014). In hindsight, McLuhan's well-known metaphor of the global village (1962) perfectly embodies this tension. While the notion of a global village carries a promise of audiences to become cosmopolitan audiences --- referring to cosmopolitanism as 'an orientation, a willingness to relate with the Other' (Hannerz, 1996: 103) --- it is, ironically, rather the second part of the concept --- village --- that is increasingly determining foreign news coverage. Studies continue to provide evidence for tendencies such as Eurocentrism and parochialism which point to an inward directed look on foreign news (Wilke, Heimprecht and Cohen, 2012). The underlying premise is generally that (international) 'news must essentially be about us' (Sonwalkar, 2004: 208). Or in the words of Peterson (1979: 120): 'the majority of foreign news is domestic news about foreign countries, not international news' and this perspective appears to thrive in contemporary news reporting (Chang, Southwell, Lee and Hong, 2012). Such statements tend to position the notion of proximity as central in the different stages of the news production process, particularly as a news selection criterion and as a determinant for politics of representation. Here, we define proximity in a very broad sense by including not only the geographical distance, but also other relationships of involvement such as cultural affinity, tourism, historical links and emotional proximity (Joye, 2010). Let us take a closer look at the related practice of domestication within the context of disaster news coverage.

\section{Domestication in disaster news coverage}

The journalistic practice of domestication generally refers to the framing of a foreign news event within the perceived national or local context of the audience (Clausen, 2004). According to Gurevitch, Levy and Roeh (1991), domesticating international events makes them comprehensible, appealing and more relevant to domestic audiences. In recent years, a growing body of research started to uncover different modes of domestication (Alasuutari, Qadir and Creutz, 2013). For instance, observing the range of constructed interconnections between the domestic and the global in news reporting on climate change, Olausson (2014: 715) has identified three discursive modes of domestication: '(1) introverted domestication, which disconnects the domestic from the global; (2) extroverted domestication, which interconnects the domestic and the global; and (3) counter-domestication, a deterritorialized mode of reporting that lacks any domestic epicenter'. This article draws on Olausson's second category, as extroverted domestication fits well with key issues in the literature on disaster reporting.

When journalists decide to domesticate a foreign disaster and hence try to render distant suffering relevant and appealing to their domestic audiences, this can have important implications. For one, a discursive portrayal as close, relevant and (inter)connected to us can raise feelings of pity or even compassion which in turn can result in helping behaviour such as 
donating money, supporting fundraising initiatives or organizing a philanthropic event (Chouliaraki, 2006). It is in this sense that representations of suffering are 'conditions of possibility for public action' (Chouliaraki, 2008: 832) as they can carry a strong moral imperative to act on those others in the name of common humanity (Silverstone, 2007). This premise also draws upon insights from psychological studies (Baumeister, Stillwell and Heatherton, 1994) which revealed that people display more compassion when they feel close or related to the Other in need. We care most about those whom we can identify or feel connected with (Moeller, 1999; Pantti, Wahl-Jorgensen and Cottle, 2012). Again, media are important in this process as such an emotional disposition of openness towards distant others (cf. cosmopolitanism) relies on technological mediation (Chouliaraki and Blaagaard, 2013). Journalists thus play a vital role in orientating (or not) the western spectator towards the Other in need. The latter is mainly located in developing countries as Belloni, Douma, Hilhorst, Holla and Kuiper (2000) note that more than $90 \%$ of all disasters occur in the Third World. When a disaster takes place in remote countries, the physical but also psychological distance leads to a situation in which the perception of the event is almost exclusively shaped by the media (Servaes and Lie, 1996). Following Hanusch (2007), we believe that distance (be it cultural, geographical or psychological) has the potential to block (emotional and practical) engagement, identification and even attention.

It is, however, important to stress that distance does not always lead to indifference, nor does proximity always lead to identification and pity. These feelings are no automatic responses to media images of suffering as audiences actively engage with media content. Categories of distance and proximity with the scene of suffering as well as the possibility of emotional involvement and identification are negotiated and established through the media, as institutions and as representations (Kyriakidou, 2011). Applying discourse analysis, Chouliaraki (2006, 2008) conceptualized these complicated relations between representations of distant suffering and the corresponding regimes of pity and identification. She identified three discourses of news that involve different degrees of (implied) moral and emotional involvement by the audience: adventure news, emergency news and ecstatic news. Adventure news refers to 'adventuristic reports on irrelevant misfortune' (Chouliaraki, 2006: 98) whereby the distant other is presented as no cause for concern or action, thus blocking any engagement, identification or feelings of compassion. Emergency news is news that produces pity in its representation of suffering as well as the option for action on distant misfortune. The audience can now identify with the remote sufferer who is still a (cultural or ethnic) other. In the case of ecstatic news, we feel for and think of the sufferer as our own, as someone who is like us. There is a relationship of reflexive identification as the audience shares with the sufferers the same humanity and threat. However, Chouliaraki (2006: 189) argues that ecstatic news rather reproduces a communitarian logic and not a cosmopolitan as the articulated 'global world' or shared humanity is restricted to the already existing micro-sphere of the West. In this article, we acknowledge the potential of practices of domestication to act as a facilitating factor in such processes of (cosmopolitan/communitarian) identification and in raising compassion.

\section{Methodology}

This study explores discourses of proximity in news reporting on global suffering. Our understanding of discourse dwells upon Jørgensen and Phillips (2002: 1) who define it as 'a particular way of talking about and understanding the world'. In other words, discourse is understood as language use as a social practice. We build on social constructionist approaches to 
discourse, in particular Critical Discourse Analysis (CDA) that 'has become one of the most influential and visible branches of discourse analysis' (Blommaert and Bulcaen, 2000: 447). Power in general and issues of power asymmetries, manipulation and exploitation in particular are the central focus of many investigations within the field. Critical discourse analysts typically stress 'patterns of domination whereby one social group is dominated by another' (Phillips, 2006: 288). Focus is put on the way these power relations are enacted, reproduced, legitimated and challenged by discourse. Discourse is thereby understood as both an expression and a mechanism of power (Jørgensen and Phillips, 2002). Furthermore, all social constructionist approaches argue that language is not neutral. Discourses create representations of the world that reflect as well as actively construct reality by ascribing meanings to our world, identities and social relations (Phillips, 2006). This implies that discourse should not be reduced to language alone. Henceforth, critical schools of discourse require that discourse should be empirically analysed within its social context (Jørgensen and Phillips, 2002): text analysis alone is not sufficient. According to Richardson (2007), CDA is mainly used to explore how discourses are realized linguistically in texts to constitute knowledge and social relations, such as a relationship of involvement, identification or compassion with a distant other. For this purpose, we have adapted Fairclough's (1992) model of CDA which consists of three dimensions: text, discursive practice (production, distribution and consumption of texts) and the wider social practice.

Following a case-based methodology, we investigate how two Belgian television stations, the public broadcaster VRT and the commercial station VTM, have domesticated international disasters in 2011. To select our cases of international news items, we used the electronic news archive ENA that is based at the University of Antwerp. The archive holds all news broadcasts on public and commercial television in Flanders [1] (Belgium). News items are pre-coded in the archive by geographical criteria into domestic news, mixed international news and foreign news. Our pool of cases is drawn from the second category as these items either involve the homecountry as an actor in the event or events in which journalists made a conscious effort to make Belgium part of the news narrative. In total, we analysed 87 news items that explicitly linked a distant crisis to Belgium, including disasters such as the tsunami and earthquake in Japan or the famine in the Horn of Africa.

\section{Results}

As indicated above, Fairclough $(1992,1995)$ identified three dimensions of CDA. In what follows, we will mainly focus on the dimension of text and particularly on the practices of domestication in news discourses on global suffering. The study explores how these representations open up spaces of identification between the audience and the sufferer.

Text

From the perspective of the majority of Belgian spectators, the selected news items depict ethnic or cultural Others. The journalistic practice of domestication helps to minimize the distance between the spectator in the comfort of his/her living room and the distant sufferer in need. By selecting specific images or highlighting particular details of a story, Belgian journalists can thus construct a sense of (emotional) proximity. Fairclough's first dimension particularly looks at such choices made by the author of the text. As the study shows, rendering a foreign disaster more 
relevant through domestication can be realized in several ways. We will now discuss the four dominant discursive modes of domestication as revealed by our analysis.

Emotional domestication. The most common strategy of domesticating distant suffering was by establishing an emotional bond. For this purpose, the broadcasters focused on human-interest stories that appeal to the audience. Manifesting itself in diverse ways, the eyewitness account was the most prominent and visible technique applied. Accounts from Belgian tourists or expats who were affected by the disaster allow the spectator to get an inside look on the event by someone who is like them. Several items featured testimonies from Belgians abroad who --- via Skype or telephone --- gave a personal and often emotional account of what has happened and how they have personally lived through the experience (e.g. 'it is terrifying', 'we fear the worst', 'panic and chaos everywhere'). Remarkably, many of these reports established the Belgians abroad as authoritative sources, qualified to make (often overtly harsh) statements about the foreign governments' dealing with the crisis and the potential risks. In some events (e.g. an airplane crash in Congo, the tsunami and earthquake in Japan, floods in Australia, ...), there were compatriots among the casualties, which is generally considered to be a determining factor for a high level of news value and attention (Joye, 2010). In these cases, the news reports were built around the fate of Belgian victims and/or their families, henceforth reducing the relevance of the non-Belgian victims --- who generally went unmentioned or were only briefly referred to at the end of the report --- despite the latter's omnipresence. The Other and his/her life are in other words made inferior to the lives of compatriots. This specific kind of domestication is, however, a less deliberate attempt of news media to invite their audience to care (cf. infra). After all, the decision to domesticate the foreign event (i.e. the focus on the compatriots among the casualties) directly stems from the fact that Belgium is actually part of the story here, henceforth challenging the very nature of the event as one of distant suffering.

Belgian journalists further constructed a sense of emotional proximity by selecting emotional images (e.g. close-ups of starving children, images of pregnant and elderly women on the run and seeking shelter), using expressive adjectives in the voice-over comments or highlighting particular emotional details of a story (e.g. interviews with parents mourning their just deceased child). We hereby briefly refer to a dominant (visual and thematic) stress on socalled 'ideal victims' (Moeller, 2002), in particularly children and elderly. When Others were given a voice, they express their worries and grieves or mourn the deaths.

This emotion- and human-interest driven coverage can be interpreted as identifying with the western moral discourse of 'civilized' humanity and compassion towards the distant victims (Konstantinidou, 2007). The particular emotional approach opens up spaces for compassion and eventually relief response, but also for a cosmopolitan outlook as the audience is invited to relate with the cultural or ethnic Other. Our findings are therefore in line with those of Alasuutari, Qadir and Creutz (2013: 699). who have found similar patterns in the domestication of the Egyptian revolt, although they subdivide this emotional strategy into two distinct modes: domestication through appealing to emotions, and domestication by linking the events with involved compatriots through eye-witness accounts.

"What's at stake for us?" A second mode of domestication that we found, relates to the attention paid to the foreign event's implications or repercussions for the audience's home country. This strategy brings the distant event to the doorstep of the Belgian spectator, but simultaneously 
manages fears of the dangers it could represent to life in Belgium (e.g. 'no reason to panic' according to the news anchor). A standard pattern that was identified starts with an enumeration of all potential risks which establishes a sense of urgency, followed by an extensive list of domestic safety procedures and measures alongside a prominent stress on the skills and expertise of the Belgian authorities involved, hence articulating a dominant discourse of control and safety. Importantly, this journalistic formula draws on Belgian experts who were interviewed on location or invited to the studio to interpret a distant event and its (anticipated) consequences for Belgium. The main question was whether the distant event could negatively affect Belgium. News items for instance discussed a potential flow of immigrants following the famine in the Horn of Africa, the implications of a volcanic eruption in Iceland for Brussels airport, or the (theoretical) consequences of the nuclear meltdown in Fukushima such as the nuclear fall-out affecting Belgium, global environmental damage and losses on the Brussels Stock Exchange. Some news items explicitly addressed the likelihood that a similar disaster could happen in Belgium. Particularly the tsunami and earthquake in Japan raised a lot of questions about the safety of Belgium's rather old nuclear plants. Other practices include travel alerts from the Ministry of Foreign Affairs following, for instance, volcano eruptions or hurricanes. In many cases, a telephone number or website was provided that spectators could call or consult in case they had questions and concerns.

Aid-driven domestication. Third, the invitation to care can also be made very explicit when the news anchor or journalist directly addresses the spectator with a call to donate money or organize an event to alleviate the suffering (e.g. 'Stop the hunger in Africa'), commonly accompanied by a series of bank account numbers. In general, this third mode of domestication establishes a very material link between an 'us' and the distant sufferers, alongside substantial references to the strategy of emotional domestication. Some items focused on (local) initiatives from individuals to raise money or act on the suffering, although the majority covered institutionalized forms of relief work by NGOs and the government. A recurrent narrative, for instance, was a news crew following compatriots who were involved in relief assistance in the affected area. Several items featured Belgian relief workers, from their departure at Brussels airport to the ground work in the disaster area, such as the famine-struck Horn of Africa in 2011. Belgian relief workers or NGOs generally deliver an interesting story to follow up which allows the news media to continue their daily reports on the disaster as they introduce a kind of 'soap' element or narrative. To a certain extent, some of these workers became familiar faces for the spectators and even celebrity figures. The victims in need were --- again --- portrayed as less relevant in comparison to these relief workers. In the long term, the relief work that is financed by public donations provides the journalist with a relevant angle to cover the aftermath of a disaster. The journalistic approach was driven by the leading question 'what has been done with our money?'.

Familiarizing the unfamiliar. Finally, an often overlooked mode of domestication is related to the format of the news broadcast and to a series of subtle stylistic, narrative and technical practices that appear unremarkable by virtue of their ubiquity. These practices are less concerned with establishing involvement as they mainly act to create a sense of familiarity and recognition. For instance, footage from foreign broadcasters was expounded by well-known voices of local expert journalists or were followed by additional comments by a popular Belgian weatherman, relief worker or celebrity who often did not contribute any new information but merely rephrased what 
has been shown or said. Other examples include the use of metaphors or short illustrations that directly relate the disaster to the spectators' daily life. For instance, in order to make the radiation risks in Fukushima tangible, the journalist briefly referred to the radiation rate of 'a X-ray taken in the hospital'. Similarly, 'the French beans that can be found in our supermarkets' introduced a topic on the practices of the food industry that impacted the famine in Africa while the Belgian national football team was the narrative peg to present an item on an airplane crash. The use of such (self-)reflexive narrative devices stems from the assumption that in terms of the experience of suffering, Belgian audiences encounter difficulties to empathically relate with people who are for instance starving as that particular experience is generally unknown to them. Journalists are thus looking for a kind of common ground to make that suffering somehow accessible and comprehensible. Furthermore, many news items started with an animation of the globe that starts in Belgium and then spins to the country affected by the disaster. Such items implicitly establish Belgium as the news item's absolute though latent point of reference. Finally, the most common way to make the unknown more familiar was by ways of journalistic narrative and foreign correspondents. Live interventions of (well-known) Belgian correspondents or explicit voiceover references to Belgium are textbook examples of linking the area of danger (the Others) with the home country. These local interventions also contribute to a 'perceived sense of reality of the event' (Clausen, 2004: 32).

To conclude this section, there is an important distinction to be made with regard to the causes of domestication. In some of the discussed cases, the element that makes domestication possible was inherent to the news event itself and has henceforth determined the news value of the event (e.g. compatriots killed --- which also raises important moral questions about the 'universal' value of human life). In most other cases, it was the journalist who decided to domesticate a pure foreign event by introducing local perspectives and actors in his/her narration such as eyewitness accounts or interviews with a Belgian expert. It is clear that the societal role and responsibility of news media is mainly manifested in the latter instance of an external element of domestication that is introduced by the journalist. Here, journalists deliberately opt to make a foreign event more relevant, appealing and less distant. Although the sufferer remains an ethnic or cultural Other, his or her suffering is no longer represented as morally irrelevant. However, discourses of inequality and hierarchy remain largely unchallenged. Moreover, a discursive side-effect of the overtly domesticated representation is the articulation of a sharp disparity between us and them in a sense that, for instance, relief aid was portrayed as 'premised on an unequal world order, whereby the poor depend on the rich' (Chouliaraki, 2006: 136).

Taken one step further, we might also problematize the implied objective of the identified domestication practices. Audiences, as individuals and as a collective, are indeed invited to care, but for whom? As hinted at above, the distant Other in need is --- due to the applied strategies of domestication --- attributed far less screen time and relevance in comparison to so-called proxies, i.e. Belgian expats, tourists and relief workers. Therefore, most news items are not so much about the distant sufferers as they are about us, the westerners. We are portrayed as a true caring nation, as Good Samaritans and the beneficiary of our pity or compassion is thus arguably rendered inferior and interchangeable. This mediated disposition of the Self as caring and benevolent persons is linked to the particular articulation of the domesticated other but also supports the idea of international relief aid as a project of self-construction (cf. Driessens, Joye and Biltereyst, 2012). Nevertheless, even a national discourse and identity of caring Westerners can play a 
positive role as they "provide a cultural lens to legitimise concern for "others" and encourage fundraising that provided much needed humanitarian assistance' (West and O'Reilly, 2015: 11).

Another problematic aspect of the practice of domestication is that excessive domestication can eventually produce 'a rather Eurocentric if not ethnocentric picture of global affairs' (Manning, 2001: 62). If proximity becomes the overall and dominant principle of international news reporting, this can result in a declining interest in events that would be pure foreign news. Acknowledging that audiences do not easily relate to foreign events, domestication can help to overcome that threshold but it simultaneously holds the risk of establishing a new threshold as distant events are increasingly assessed on their potential to be domesticated.

\section{Discursive practices}

As discourse is context-dependent (Richardson, 2007), a key characteristic of CDA is to analyse text in its context. News is the outcome of a broad range of specific professional and institutional practices which limit the choice of journalists (Fairclough, 1995). Especially in the case of reporting on disasters, journalists regularly find themselves confronted with a number of constraining contextual factors such as a difficult access to the disaster area, incomplete or unconfirmed reports, and government policy (Apps, 2009). Of interest to our study are a number of contextual dimensions that concern the editorial policy of both television stations. One contextual parameter that is of particular significance for us is the balance between domestic and foreign news. Although the public service broadcaster VRT and commercial channel VTM both enjoy a good reputation regarding the quality and amount of their foreign news, they tend to adhere to a Eurocentric or western vision of the world in their news reporting, including the adoption of domestication practices (Joye and Biltereyst, 2007). The corporate mission of a television network is another significant element of this editorial context. Despite a very high level of similarity in the events selected and the footage shown, some subtle discursive differences in the applied modes of domestication between VRT and VTM are noticeable. For instance, commercial channel VTM domesticates more foreign events and does so in a more intensive way than its publicly funded counterpart. While VRT journalists contacted only one Belgian abroad via Skype in addition to three stand-ups from the disaster area, VTM journalists made use of fifteen testimonies via Skype and eight via telephone alongside six live interventions. In the past, several editors of the VTM news have explicitly and repeatedly stated to focus more on the news that matters to the local Flemish audience, resulting in a higher proportion of domesticated international news. Remarkable in this respect is VTM's discursive stress on Flanders. While all items of VRT referred to 'Belgium' or 'Belgians', journalists of VTM discursively reduced their intended audience to the smaller Flemish community by consistently referring to 'Flanders' and 'Flemings'. Other differences between the two stations deal with the use of sensational adjectives and sound-bites, and the tendency to personalize the news events. Public broadcaster VRT made less use of these practices.

\section{Social practices}

News discourse is also permeated by structures, institutions and values from outside the newsroom such as economy, politics and ideology (Richardson, 2007). This dimension of Fairclough's model essentially refers to ideological and hegemonic processes (Blommaert and 
Bulcaen, 2000). Although van Dijk (2009: 199) admits that it is theoretically and empirically impossible to provide a complete and detailed 'account of the ideologies involved and the structures of news that are controlled by them', he states that a polarisation between the in-group (the Self) and the out-group (the Other) is characteristic of many such ideological structures. In terms of the presented study, the practice of domestication itself already refers to such a sociocultural polarisation. News items about the Other first need to be domesticated in order to gain some relevance or importance. An additional element in the news coverage is the fact that Belgium is mainly represented in a positive way, either stepping in to help the Other as a caring and benevolent community or being firmly in control of the situation by demonstrating agency and effective crisis management skills. The tendency towards such a journalism by proximity further resonates with the Orientalist (cf. Saïd, 1987) discourse of civilized West (the in-group, identified as superior) versus barbarian Other (the out-group, categorized as inferior and represented in a negative way). This by mediation constituted hierarchy is moreover a reflection of the well-known hierarchies of capitalism in which the rich are valued more than the poor. International news coverage is permeated by such power relations of inequality. Coming full circle, Olausson (2014: 719) additionally claims that these 'polarized discursive constructions of Us and Them in the construction of power' are clearly manifested in the mode of extroverted domestication.

\section{Conclusion}

This article acknowledged the potential of news media to invite domestic audiences to care for and relate with a distant other in need. By framing the suffering within the horizon of relevance and the life sphere or context of the Belgian spectator, domesticating global suffering articulates a mediated ethics of care (Cottle, 2009) as it creates possibilities for news media to engage their audiences in compassion, identification and action. It brings the suffering closer and establishes an experiential overlap that allows domestic audiences to emotionally relate to an Other in need. Nonetheless, there are some significant setbacks to acknowledge with regard to the practice of domestication such as the emerging danger of reproducing an ethnocentric view of the world. In line with earlier work suggesting that (foreign) news must essentially be about us (Sonwalkar, 2004: 208), our findings support the claim that news on global suffering continues to focus mostly and mainly on $u s$ and our community. In this respect, this study emphasizes the key role of proximity within international news reporting. As most disasters occur in non-western countries, news media thus play a vital role in minimizing the mental and emotional distance, and in inviting the audience to care. Referring to the key notions of identification and domestication, the central question is eventually about whom we can relate to or whom we can feel compassionate about. What is at stake is the question of whose suffering will be domesticated by news media and whose suffering will be constructed as inconsequential and morally irrelevant.

The four identified discursive modes of domestication disclose the potential of news media to invite local audiences to relate with a distant Other, and to support feelings of identification. This implies a key democratic role of journalists in the mediated construction of suffering and in opening up spaces for compassion, relief help and policy interventions. Domestication as a journalistic practice can thus be seen as a deliberate and important choice to insert global suffering with local relevance. While the focus of this contribution lies on the perspective of the news media as producers of domesticated discourses, future empirical research 
is needed to assess how and to what extent the audience actually engages with these news discourses and, hence, accepts or rejects the invitation to care.

\section{Notes}

[1] Flanders is the Dutch-speaking Northern part of Belgium.

\section{References}

Alasuutari, P., Qadir, A. and Creutz, K. (2013) 'The Domestication of Foreign News', Media, Culture \& Society 35(6): 692-707.

Apps, P. (2009) 'Reporting Humanitarian Crises', in J. Owen and H. Purdey (eds) International News Reporting, pp. 253-272. Malden: Wiley-Blackwell.

Baumeister, R.F., Stillwell, A.M. and Heatherton, T.F. (1994). Guilt: An Interpersonal Approach. Psychological Bulletin, 115(2), 243-267.

Belloni, H., Douma, N., Hilhorst, T., Holla, J. and Kuiper, G. (2000) Representation of Natural Disasters in Dutch Newspapers. www.disasterstudies.wur.nl

Benthall, J. (2010) Disasters, Relief and the Media. London: I.B. Tauris.

Berglez, P. (2013) Global Journalism. New York: Peter Lang.

Biltereyst, D. and Desmet, L. (2010) 'One Day of Foreign and International News' in J. Gripsrud and L. Weibull (eds) Media, Markets and Public Spheres, pp. 195-217. Bristol: Intellect Books.

Blommaert, J. and Bulcaen, C. (2000) 'Critical Discourse Analysis', Annual Review of Anthropology 29: 447-466.

Boltanski, L. (1999) Distant Suffering. Cambridge: Cambridge University Press.

Chang, T., Southwell, B., Lee, H. and Hong, Y. (2012) 'A Changing World, Unchanging Perspectives', International Communication Gazette 74(4): 367-384.

Chouliaraki, L. and Blaagaard, B. (2013) 'Introduction', Journalism Studies 14(2): 150-155.

Chouliaraki, L. (2006) The Spectatorship of Suffering. London: Sage.

Chouliaraki, L. (2008) 'The Media as Moral Education', Media, Culture \& Society 30(6): 831852.

Clausen, L. (2004) 'Localizing the Global: 'Domestication' Processes in International News Production', Media, Culture \& Society 26(1): 25-44.

Cottle, S. (2009) Global Crisis Reporting. Berkshire: Open University Press.

Driessens, O., Joye, S. and Biltereyst, D. (2012) 'The X-factor of Charity', Media, Culture \& Society 34(6): 709-725.

Fairclough, N. (1992) Discourse and Social Change. Cambridge: Polity press.

Fairclough, N. (1995) Media Discourse. London: Edward Arnold.

Franks, S. (2008) 'Getting into Bed with Charity', British Journalism Review 19(3): 27-32.

Gurevitch, M., Levy, M. and Roeh, I. (1991) 'The Global Newsroom', in P. Dahlgren and C. Sparks (eds) Communication and Citizenship, pp. 195-216. London: Routledge.

Hanusch, F. (2007) 'Publishing the Perished', Media International Australia 125: 29-40.

Hannerz, U. (1996) Transnational Connections. London: Routledge.

Höijer, B. (2004) 'The Discourse of Global Compassion', Media, Culture \& Society 26(4): 513531.

Jørgensen, M. and Phillips, L. (2002) Discourse Analysis as Theory and Method. London: Sage. 
Joye, S. and Biltereyst, D. (2007) 'All Quiet on the ...? An Analysis of Foreign and International News Coverage on VRT and VTM', in M. Hooghe, K. De Swert and S. Walgrave (eds) De Kwaliteit van het Nieuws, pp. 71-84. Leuven: Acco.

Joye, S. (2010) 'News Media and the (De)Construction of Risk', Catalan Journal of Communication \& Cultural Studies 2(2): 253-266.

Kitch, C. and Hume, J. (2007) Journalism in a Culture of Grief. New York: Routledge.

Kyriakidou, M. (2011) Watching the Pain of Others (unpublished PhD-dissertation). London: London School of Economics and Political Science.

Manning, P. (2001) News and News Sources. London: Sage.

McLuhan, M. (1962) The Gutenberg Galaxy. Toronto: University of Toronto Press.

Moeller, S.D. (1999) Compassion Fatigue. London: Routledge.

Moeller, S.D. (2002) 'A Hierarchy of Innocence', International Journal of Press/Politics 7(1): $36-56$.

Olausson, U. (2014) 'The Diversified Nature of "Domesticated" News Discourse', Journalism Studies 15(6): 711-725.

Pantti, M. (2009) 'Wave of Compassion', in U. Kivikuru and L. Nord (eds) After the Tsunami, pp. 83-106. Göteborg: Nordicom.

Pantti, M., Wahl-Jorgensen, K. and Cottle, S. (2012) Disasters and the Media. New York: Peter Lang.

Peterson, S. (1979) 'Foreign News Gatekeepers and Criteria of Newsworthiness', Journalism Quarterly 56(1): 116-125.

Richardson, J.E. (2007) Analysing Newspapers. New York: Palgrave Macmillan.

Saïd, E. (1987) Orientalism. New York: Penguin.

Servaes, J. and Lie, R. (eds) (1996) Communication and Social Change. Leuven: Acco.

Silverstone, R. (2007) Media and Morality. Cambridge: Polity Press.

Sonwalkar, P. (2004) 'News Imperialism: Contra View from the South', in C. Paterson and A. Sreberny (eds) International News in the 21st Century, pp. 111-126. London: John Libbey Publishing.

Tomlinson, J. (1999) Globalization and Culture. Cambridge: Polity. van Dijk, T.A. (2009) 'News, Discourse, and Ideology', in K. Wahl-Jorgensen and T. Hanitzsch (eds) The Handbook of Journalism Studies, pp. 191-204. New York: Routledge.

West, B. and O'Reilly, R. (2015) 'National Humanitarianism and the 2004 Indian Ocean Tsunami', Journal of Sociology: 1-15.

Wilke, J., Heimprecht, C. and Cohen, A. (2012) 'The Geography of Foreign News on Television', International Communication Gazette 74(4): 301-322. 